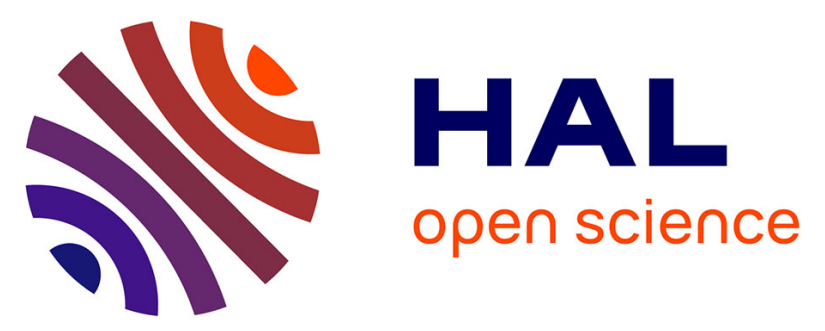

\title{
The importance of a sub-region on chromosome 19q13.3 for prognosis of multiple myeloma patients after high-dose treatment and stem cell support: a linkage disequilibrium mapping in and
}

\author{
Annette J. Vangsted, Tobias Wirenfeldt Klausen, Peter Gimsing, Niels \\ Abildgaard, Niels F. Andersen, Henrik Gregersen, Bjørn Andersen Nexø, Ulla \\ Birgitte Vogel
}

\section{- To cite this version:}

Annette J. Vangsted, Tobias Wirenfeldt Klausen, Peter Gimsing, Niels Abildgaard, Niels F. Andersen, et al.. The importance of a sub-region on chromosome 19q13.3 for prognosis of multiple myeloma patients after high-dose treatment and stem cell support: a linkage disequilibrium mapping in and. Annals of Hematology, 2010, 90 (6), pp.675-684. 10.1007/s00277-010-1105-z . hal-00594494

\author{
HAL Id: hal-00594494 \\ https://hal.science/hal-00594494
}

Submitted on 20 May 2011

HAL is a multi-disciplinary open access archive for the deposit and dissemination of scientific research documents, whether they are published or not. The documents may come from teaching and research institutions in France or abroad, or from public or private research centers.
L'archive ouverte pluridisciplinaire $\mathbf{H A L}$, est destinée au dépôt et à la diffusion de documents scientifiques de niveau recherche, publiés ou non, émanant des établissements d'enseignement et de recherche français ou étrangers, des laboratoires publics ou privés. 


\section{The importance of a sub-region on chromosome 19q13.3 for prognosis of multiple myeloma patients after}

high-dose treatment and stem cells support: A linkage disequilibrium mapping in $R A I$ and $C D 3 E A P$.

Annette J. Vangsted ${ }^{1}$, Tobias W. Klausen ${ }^{2}$, Peter Gimsing ${ }^{3}$, Niels Abildgaard ${ }^{4}$, Niels F. Andersen ${ }^{5}$, Henrik

Gregersen $^{6}$, Bjørn A. Nex $\varnothing^{7}$, and Ulla Vogel ${ }^{8,9,10}$

1) Dept. of Oncology and Haematology, Roskilde Hospital, Copenhagen University, DK-4000 Roskilde, Denmark

2) Dept. of Haematology, University Hospital of Copenhagen at Herlev, DK-2730 Herlev, Denmark

3) Dept. of Haematology, University Hospital of Copenhagen at Rigshospitalet, DK-2100 Copenhagen, Denmark.

4) Dept. of Haematology, Odense University Hospital, DK-5000 Odense, Denmark

5) Dept. of Haematology, Aarhus University Hospital, DK-8000 Aarhus, Denmark

6) Dept. of Haematology, Aalborg University Hospital, DK-9100 Aalborg, Denmark

7) Institute of Human Genetics, University of Aarhus, DK-8000 Aarhus C, Denmark.

8) National Food Institute, Technical University of Denmark, DK-2860 Copenhagen

9) Institute for Science, Systems and Models, Roskilde University, DK-4000 Roskilde, Denmark

10) National Research Centre for the Working Environment, DK-2100 Copenhagen, Denmark

\section{To whom correspondence should be addressed:}

Annette Vangsted, MD, Clinical associate professor

Department of Oncology and Haematology

Roskilde Hospital, Copenhagen University

Køgevej 9-13, 4000 Roskilde

Email: avag@regionsjaelland.dk

Phone: +4546333200 Fax: +45 46326994

Key words: multiple myeloma; SNP, chromosome 19q13.3, outcome, interferon- $\alpha$, thalidomide, bortezomib. Abbreviations: MM, multiple myeloma; OS, overall survival; TTF, time-to-treatment failure; HDT, high-dose treatment, SNP; single nucleotide polymorphism; LD, linkage disequilibrium (LD); CI, confidence interval; RR, relative risk; $E R C C 1$, excision-repair cross-complementing 1; ERCC2 excision-repair cross-complementing 2;RAI, RelA associated inhibitor (also named PPP1R13L, protein phosphatase 1, regulatory (inhibitor) subunit 13 like and 
iASPP); CD3EAP, CD3e molecule epsilon associated protein (also named $A S E-1$, anti-sense to ERCC1); NER,

nucleotide excision repair;

\section{Authors' contribution:}

Annette J. Vangsted: Conception and design, collection of data, analysis and interpretation of data, drafting the article, approval of the version to be published.

Tobias W. Klausen: Conception and design, analysis and interpretation of data, approval of the version to be published. Peter Gimsing: Collection of data, analysis and interpretation, revising the manuscript critically, approval of the version to be published

Niels Abildgaard: Analysis and interpretation, revising the manuscript critically, approval of the version to be published.

Niels F. Andersen: Analysis and interpretation, revising the manuscript critically, approval of the version to be published

Henrik Gregersen: Analysis and interpretation, revising the manuscript critically, approval of the version to be published

Bjørn A Nexø: Conception and design, determination of genotypes, analysis and interpretation of data, drafting the article, approval of the version to be published.

Ulla Vogel: Conception and design, analysis and interpretation of data, drafting the article, approval of the version to be published. 


\begin{abstract}
The gene $R A I$ was originally described as an inhibitor of RelA/p65 subunit of NF- $\mathrm{BB}$. Here, we analyze the association between genetic variation in the genes $R A I$ and $C D 3 E A P$ and outcome of 348 myeloma patients treated with high-dose treatment (HDT), 146 patients treated with INF- $\alpha$ as maintenance treatment, 177 patients treated with thalidomide and 74 patients treated with bortezomib at relapse and address if the effects of polymorphisms in $C D 3 E A P$ and $R A I$ are modified by a functional polymorphism in $N F K B 1$.

By linkage disequilibrium mapping we found that variant alleles of several polymorphisms in a sub-region of 19q13.3, spanning the regions $R A I$-intron1-1 to $R A I$ intron1-3 and the region exon1 to exon3-6 in $C D 3 E A P$, were associated with prolonged time-to-treatment failure $(\mathrm{TTF})(\mathrm{p}=0.003)$ and overall survival $(\mathrm{OS})(\mathrm{p}=0.02)$. Haplotype analyses revealed that none of the haplotype were stronger associated to TTF or OS than the two strongly linked SNPs; RAI-intron1-1
\end{abstract} (rs4572514) and CD3EAP G-21A (rs967591).

The association of RAI-intron1-1 and CD3EAP G-21A with TTF was independent of NFKB1 -94 ins/del, but homozygous ins-allele carriers who were also variant allele carriers of $R A I$-intron1-1 or $C D 3 E A P G$-21Ahad the longest OS. Among patients treated with INF- $\alpha$, or thalidomide, no effect was seen in relation to genotype. Our results indicate that polymorphism in $R A I$ and $C D 3 E A P$ are associated with outcome of myeloma patients treated with HDT. Combination analyses with the functional polymorphism in NFKB1 suggest that a possibly functional effect of RAI or $C D 3 E A P$ could be related to $\mathrm{NF}-\kappa \mathrm{B}$ availability. 


\section{Introduction}

Multiple myeloma (MM) is an incurable B-cell malignancy. Younger patients are treated with high-dose treatment (HDT) and stem cells support. Despite this intensive treatment strategy, huge variation in treatment outcome is seen, with some patients suffering from early and aggressive recurrence of the disease. Understanding the mechanism of these differences may help us to establish new and better treatment strategies. Response to chemotherapy may reflect the effect of genetic variation related to differences in DNA repair, apoptosis and immune response.

A small region on the human chromosome 19q13.3 may be important for the development of cancers of the breast, lung and skin as well as outcome of chemotherapy (figure 1) [1-4]. The region encompasses 4 genes. Two genes, related to nucleotide excision repair (NER), the excision-repair cross-complementing 1 (ERCC1) and ERCC2 (XDP), are involved in repair of bulky DNA damage caused by chemotherapy [5]. The gene product of the third gene $R A I$ (RelA inhibitor; also named $i A S P P$ or protein phosphatase 1, regulatory (inhibitor) subunit 13 like $(P P P 1 R 13 L)$ ) [6;7] was identified as a protein that binds to the NF- $\kappa \mathrm{B}$ subunit $\mathrm{p} 65 / \mathrm{RelA}$ and inhibits its transcriptional activity [8]. The inhibition of NF- $\mathrm{KB}$ transcription induced apoptosis [8]. Later studies revealed that the RAI protein also inhibits apoptosis by binding to 553 [9]. Recently, over expression of $R A I$ has been shown to increase tumor formation in primary mouse embryonic fibroblasts [7]. These data support the hypothesis that RAI may function as an oncogene. The fourth gene in the chromosome region 19q13.3 is named CD3EAP (CD3e molecule epsilon associated protein; alias $A S E 1$ (anti-sense to ERCC1); alias CAST)) [5]. The gene was cloned by use of autoimmune serum from a patient with interstitial cystitis [10]. It is orientated anti-sense to and overlaps with the ERCC1 gene and it has therefore been suggested, that the mRNA of $C D 3 E A P$ may bind the transcript of ERCC1 and inhibit translation [11]. This hypothesis was not supported by scientific results. The protein is localized in the fibrillar centers of the nucleus, which may indicate a function in ribosomal RNA transcription [11]. Another study by Yamazaki et al. suggests that the gene product of CD3EAP mediates activation signals, important for IL-2 production [12]. In a recent study of fifty-nine NCI60 human tumour cell lines, sensitivity to anticancer drugs correlated positively with the variant A-allele of the polymorphism $C D 3 E A P$ G-21A [13]. At present, the function of the gene is not clearly established. We have earlier shown that genetic variation in $C D 3 E A P$ is associated with outcome in patients with multiple myeloma treated with HDT [4]. Patients carrying the variant A-allele of CD3EAP G-21A had a significant longer TTF and OS after HDT [4]. These results support the notion that the genomic region influence outcome of chemotherapy. 
The gene $N F K B 1$ encodes the p50 subunit and its precursor p105. We have previously shown, that the polymorphism NFKB1 -94 ins/del is associated with outcome of interferon- $\alpha$ (INF- $\alpha$ ) maintenance treatment after HDT in patients with MM [14].

The aim of the present study was to gain further knowledge of impact of genetic variation in the human chromosome region 19q13.3, by fine mapping associations between many single nucleotide polymorphisms (SNPs) with outcome of 348 myeloma patients treated with HDT. Furthermore, we analysed if genes in the chromosome sub-region19q13.3 interplay with the polymorphism in $N F K B 1$ in relation to outcome of multiple myeloma treated with HDT and maintenance treatment with interferon- $\alpha$.

\section{Materials and methods}

\section{Subjects, clinical data, response criteria, eligibility criteria, and treatment for patients included in SNP analysis.}

Subjects, clinical data, response criteria, and eligibility criteria have previously been described in detail $[4 ; 14 ; 15]$. Briefly, patients diagnosed with MM and treated with HDT and stem cell support from August 1994 to August 2004 were recruited from four participating centres in Denmark. Three hundred forty-eight patients were included in the study. Staging was according to Durie and Salmon and the International Staging System (ISS). Time-to-treatment failure (TTF) and overall survival (OS) were calculated from date of stem cell infusion to date of progression or death. Progression was defined by a more than $25 \%$ increase in serum M-protein or $25 \%$ increase in immunoglobulin levels above upper normal levels, confirmed by 2 separate measurements within a 1 -month interval. Increase in bone marrow infiltration of plasma cells by $25 \%$, and increase of Bence-Jones proteinuria to more than $1.0 \mathrm{~g} / 24 \mathrm{hr}$ or other signs of progression such as hypercalcaemia, progressive skeletal disease or soft-tissue plasmacytoma were also considered as progression. The occurrence of other malignancies and death without progression was regarded as events not related to progression. These patients were included in the analysis of OS, but they were excluded at time of death in the analysis of TTF. Complete response (CR) after HDT was defined by the disappearance of M-protein form serum and urine, as detected by agarose gel electrophoresis and less than 5\% plasma cells in the bone marrow aspirate. Partial response (PR) was defined by a reduction of at least $50 \%$ in the initial serum M-protein concentration and a reduction of light chain proteinuria to less than $0.2 \mathrm{~g} / 24$ hours. Time-to-next treatment (TNT) was used as follow-up after relapse treatment and was defined as the period from start of relapse treatment to start of new relapse treatment, progression without new treatment or death. 
Induction therapy was 3 series VAD (vincristine, doxorubicin and dexamethasone) or 2-3 series of cyclophosphamide $1 \mathrm{~g} / \mathrm{m}^{2}$ i.v. on day 1 combined with dexamethasone $40 \mathrm{mg}$ daily p.o., on days 1-4 and days 9-11 (total dose $320 \mathrm{mg}$ for each series) repeated every 3 weeks. Peripheral blood stem cells were harvested at regeneration after cyclophosphamide priming, and the patients thereafter underwent high-dose chemotherapy with melphalan $\left(200 \mathrm{mg} / \mathrm{m}^{2}\right)$ followed by stem cell support. Fifty-three patients received a second HDT up-front. Maintenance therapy with IFN- $\alpha$ was implemented 3 months after HDT according to standard treatment practise in the particular region (median 105 days) [14]. Two-hundred and forty-tree patients experienced relapse which required treatment. Among these patients 177 were treated with thalidomide and 74 were treated with bortezomib [16].

PBMC was purified from 292 leukapheresis products by buffy coat preparation. From 56 patients 10 times $10 \mu \mathrm{m}$ sections were collected from paraffin embedded bone marrow samples. Material was not available for 19 patients undergoing HDT and these patients were not included in the study.

The study was approved by the Danish Ethical Committee (01-158/03).

\section{DNA purification}

DNA for analysis was purified from PBMC by the salting out method [17] or from paraffin embedded tissue by phenol extraction as described elsewhere [18].

\section{Genotyping of single nucleotide polymorphisms}

The XPD (ERCC2) SNP rs238406, rs238407, rs2097215, the RAI SNPs rs10422489, rs4544343, rs6966, rs12986272, rs10402584, rs10402393, rs4572514, rs4803816, rs95947, rs928911, rs4803817, nr.106, rs10412761 and the CD3EAP (ASE1) SNPs rs8113779, rs2013521, rs735482, rs762562, rs2336219, rs3212986, rs3212985, rs1007616, and the ERCC1 SNPs rs3212969, rs3212961, rs2298881, and rs1319052 were tested using a Sequenom® platform (San Diego, California) and the iPLEX gold reaction. Each PCR reaction contained $10 \mathrm{ng}$ of genomic DNA, $0.5 \mathrm{U}$ HotStar Taq from Qiagen (Hilden, Germany), 1.25 x Enzyme Buffer (Qiagen), $3.5 \mathrm{mM} \mathrm{MgCl}$. and $1 \mathrm{mM}$ of each deoxynucleotide. The primers were added to a final concentration of $500 \mathrm{nM}$ each. The total reaction volume was $4 \mu \mathrm{l}$. PCR reactions with primers of each plex were performed in 384 well plates with V-shape by performing a 15 min preheat to $94 \mathrm{C}$ followed by cycling the samples 45 times, $94 \mathrm{C}$ for $20 \mathrm{sec}, 56 \mathrm{C}$ for $30 \mathrm{sec}$ and $72 \mathrm{C}$ for $1 \mathrm{~min}$, followed by $3 \mathrm{~min}$ at $72 \mathrm{C}$. The plates were stored at -20 C. Treatment with Shrimp Alkaline Phosphatase and extension with molecular weightmodified nucleotides was performed according to the manufacturer's recommendations. The reactions were cleaned 
with resin and spotted on SpectroChip arrays according to the manufacturer's recommendations. The reactions were analyzed by MALDITOF mass spectrometry on the Sequenom equipment, and the results were analyzed using the MassARRAY Type 4.0 (Sequenom).The primers and probes are presented in supplement Table 1. For $X P D$-exon23 (rs13181); XPD-exon10 (rs1799793), RAI-intron8-1 (rs1970764), ASE1-exon1 (rs967591), ERCC1-exon4 (rs317770), and NFKB1 ATTG (rs28362491) the method has been previously reported [4;14;19]

\section{Statistical methods}

SPSS statistical software was used for all calculations (SPSS for Windows, Rel. 14.0.0. 2005, Chicago: SPSS Inc.). All tests were two-sided and P-values $<0.05$ were regarded as statistically significant. Fisher's exact test was used to compare categorical variables and the Mann-Whitney test was used to compare continuous and categorical variables. Kaplan-Meier method and the log rank test were used to compare TTF and OS between groups. The Cox proportional hazard model and log-likelihood statistics were applied for univariate analyses and covariates and for multivariate analysis.

\section{Results}

\section{Study population}

Three-hundred and forty-eight myeloma patients were treated with HDT and stem cell support. The patient characteristics are presented in Table 1. The median age of the patients was 56 years and the study included 59\% males. The median follow-up of all patients still alive was 93.4 months (range, 54.6-174.2 months). At follow up 208 patients had died. The median OS was 69.8 months (60.5-81.6 months). The median TTF was 27.7 months (23.4-30.8 months). One-hundred and forty-six patients were treated with INF- $\alpha$ maintenance treatment.

\section{The genotype frequencies of XPD, RAI, CD3EAP and ERCC1 and their influence on TTF, OS and response to treatment}

All genetic variation in the chromosomal region was previously identified by sequencing of breast cancer patients and healthy controls [20]. The genotype frequencies and association of minor allele frequency with TTF and OS after HDT are summarized in supplementary Table 2. For completeness of the investigation, we have also included previously reported SNPs in the region [4]. The percentage of successful genotype determinations was low for a number of polymorphisms, reflecting that the mass-spectrometry-based genotyping was unsuccessful for DNA isolated from 
paraffin embedded tissues, which constituted $16 \%$ of the samples. The outcome for homozygous wild type carriers versus variant carriers association of single polymorphisms in XPD, RAI, CD3EAP and ERCC1 is illustrated in Figure 2 A sub-region of $19 \mathrm{q} 13.3$ on the chromosome spanning the regions $R A I$-intron1-1 to $R A I$-intron1-3 and the region exon1 to exon3-6 in CD3EAP, was significantly associated with TTF and OS in myeloma patients treated with HDT, and carriers of the variant allele of the SNPs had prolonged TTF and OS. There was no difference in the allele frequencies among patients dependent on the participating centres, and there was no difference in genotype distribution in relation to age, $\beta 2$-mcroglobulin, creatinine, albumin, Durie-Salmon stage, ISS stage, gender, tandem HDT upfront, INF- $\alpha$ maintenance treatment, second HDT at relapse, treatment with thalidomide or bortezomib (supplementary table 3). There was no association between allele frequencies and response to treatment.

\section{Haplotype analysis of $X P D, R A I, C D 3 E A P$ and $E R C C 1$ and the influence on TTF and OS in myeloma patients treated with HDT.}

Pair-wise linkage disequilibrium and block structure of $33 \mathrm{SNP}^{\prime}$ in the genes $X P D, R A I, C D 3 E A P$ and $E R C C 1$, using the haplo-view software program, are illustrated in supplementary Figure 1. Two haplotype analyses were generated for the sub-region 19q13.3. One haplotype analysis covered the genes RAI, CD3EAP and ERCC1 (rs4803816, rs967591, rs3212985 and rs1319052), and the other haplotype covered the gene CD3EAP (rs8113779, rs735482, rs3212986 and rs 1007616). The two haplotype analyses included $97.6 \%$ and $85 \%$ of all patients with available genotype data in the study, respectively. None of the haplotype analyses revealed stronger association to TTF or OS than the two most significant SNP's; RAI-intron1-1 (rs4572514) and ASE1-exon1 (rs967591).

\section{Combination of SNPS}

Supplementary Table 4 and Figure 3 show the combination analysis of NFKB1 -94ins/del, CD3EAP G-21A and RAIintron1-1. When genotypes of $C D 3 E A P$ or $R A I$ were combined with genotypes of $N F K B 1$-94ins/del, carriers of the variant A-allele of $C D 3 E A P \mathrm{G}-21 \mathrm{~A}$ or the variant $\mathrm{C}$-allele of $R A I$-intron1-1, a prolonged TTF was seen independently of the NFKB1-94ins/del genotype, in contrast to OS, where an increase in median survival to more than 10 years, only was seen among carriers of the variants alleles of either $C D 3 E A P \mathrm{G}-21 \mathrm{~A}$ or $R A I$-intron1-1, when combined with the wild type ins-allele of NFKB1-94ins/del. 


\section{Analysis of the effect of genotypes on TTF and OS in patients treated with INF-a, thalidomide and bortezomib.}

TTF and OS were compared in groups subdivided by genotype and INF- $\alpha$ treatment. Among patients treated with INF$\alpha$, carriers of the variant C-allele or RAI-intron1-1 had a significant prolonged TTF and OS (56.3 months and not reached, respectively) as compared to homozygous T-allele carriers (30.5 months and 74.4 months, respectively). However, when tested in a multivariate Cox analysis, the analysis showed that the difference in TTF was not related to treatment with INF- $\alpha$ and only a trend was found for OS ( $(\mathrm{p}=0.06)$. No association between treatment outcome of thalidomide and bortezomib with genotype was found, except for carriers of the variant A-allele of CD3EAP-G-21A, where a significantly prolonged TNT and OS was seen. We explored combination analyses of NFKB1 -94ins/del, CD3EAP G-21A and RAI-intron1-1 in relation to treatment with INF- $\alpha$, and the results are shown in Table 2. Patients treated with INF- $\alpha$, who carried two copies of the T-allele of RAI-intron1-1 and the variant del-allele of NFKB1 94ins/del had a significantly shorter TTF, and patients who carried the variant del-allele of NFKB1 -94ins/del and either of the wild type alleles of $C D 3 E A P$ G-21A or RAI-intron1-1 had a significant shorter OS survival as compared to carriers of the wild type ins-allele of NFKB1 -94ins/del in combination with the variant alleles of either CD3EAP G21A or RAI-intron1-1 (figure 4).

\section{Discussion}

We have explored a sub-region in 19q13.3 by fine mapping associations between many single nucleotide polymorphisms (SNPs) and treatment outcome in 348 myeloma patients treated with HDT. We found that several polymorphisms in a region spanning the genes $R A I$-intron1-1 and CD3EAP-exon3-6 were significantly associated with TTF and OS in myeloma patients. The effects of the polymorphisms RAI-intron1-1 and CD3EAP G-21A on gene functions are not known. Both SNPs are located in the 5'region of their respective genes, the first intron and the 5'UTR, respectively, but none of them are located in the reading frame, and one may speculate that they affect transcription efficiency or gene regulation. In the studied population of patients, the effects of polymorphisms in $R A I$ and $C D 3 E A P$ were similar, and we found a pair wise linkage disequilibrium between $R A I$-intron1-1 (rs4572514) and CD3EAP G-21A (rs967591) of $\mathrm{D}^{\prime}=0.94$, suggesting that they detect the same biological effect.

The gene $R A I$ was initially identified as an inhibitor of the NF- $\mathrm{kB}$ subunit $\mathrm{p} 65$. The pro-inflammatory NF- $\mathrm{kB}$ consists of the dimer p50/p65. The NFKB1 -94ins/del ATTG polymorphism is an insertion/deletion of four bases in the promoter region of the NFKB1 gene encoding both of the NF-KB transcription factors, p50 and p105. We therefore combined the polymorphism NFKBI -94ins/del with polymorphism in RAI-intron1-1 in relation to outcome of 
treatment. From previous results we know that TTF and OS are not significantly affected by the polymorphism NFKBI -94ins/del [19]. The deletion produces lower transcripts levels in luciferase reporter systems, and thus results in lower levels of NF-kB p50 [21]. In myeloma patients treated with HDT, the effect on TTF for the polymorphism RAI-intron11 was independent of the polymorphism NFKB1 -94ins/del. Assuming that RAI is indeed an inhibitor of NF-kB p65,

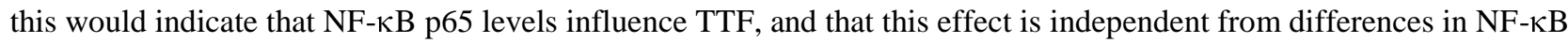
p50 levels. For OS, the effect of $R A I$-intron1-1 was in favour of patients also carrying the wild type ins-allele of $N F K B I$ -94ins/del, and these findings support that the classical NF- $\mathrm{kB}$ pathway (p65/p50 dimer) is involved in survival of myeloma patients after HDT.

In this population of patients a subgroup of 146 patients were treated with INF- $\alpha$ as maintenance treatment after HDT. The decision of starting INF- $\alpha$ treatment was solely based on different treatment guidelines on starting post-HDT maintenance treatment at the participating departments and therefore not connected with selection bias. Interferon and NF-KB are central for the regulation of apoptosis, cell growth and for modulation of the immune system [22;23]. From previous results, we know that the polymorphism NFKB1 -94ins/del influences outcome for patients treated with INF- $\alpha$ as maintenance treatment [14]. Among patients treated with INF- $\alpha$, carriers of the variant del-allele carriers of NFKB1 94ins/del and the wild type T-allele of $R A I$-intron1-1 had a significant shorter TTF and OS survival as compared to double homozygous wild type carriers. The effect of INF- $\alpha$ may therefore depend on a normal transcription level of the

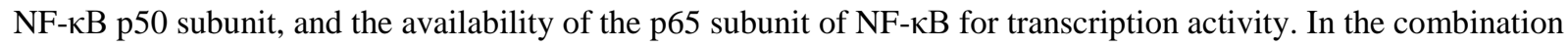
analyses $C D 3 E A P$ G-21A AG+GG was similar to $R A I$-intron1-1 $\mathrm{TC}+\mathrm{CC}$, probably due to their strong linkage (supplementary figure 1). In general, RAI-intron1-1 had the stronger effect, perhaps indicating that RAI-intron1-1 is the biologically relevant polymorphism. In carriers of the variant A-allele of $C D 3 E A P-\mathrm{G}-21 \mathrm{~A}$, a significantly prolonged OS was seen for patients treated with bortezomib. If true, this result could be interesting because Hideshima et al recently found that bortezomib treatment increases NF- $\mathrm{kB}$ dependent transcription in myeloma cells in vitro via activation of two upstream NF-kB-activating kinases RIP2 and IKК $\beta$ [24]. However, in our cohort of patients only few patients were treated with bortezomib, and consequently the statistical power to detect interaction with bortezomib was limited. No effect on TNT was seen, and combination analysis of RAI-intron1-1 did not reveal the same statistically significant results (table 2). We conclude that the polymorphisms RAI-intron1-1 and CD3EAP-exon3-6 are associated with outcome of myeloma patients treated with HDT. The effects of the polymorphisms on gene function are unknown, as well as the function of the genes $R A I$ and in particular CD3EAP. The findings should be sought replicated in an independent study group of similarly treated multiple myeloma patients. Combination analyses with the functional 
polymorphism in $N F K B 1$ suggest that a possibly functional effect of $R A I$ or $C D 3 E A P$ could be related to NF- $\mathrm{NB}$ availability. This hypothesis should be tested at the molecular level.

\section{Legends to figures}

Figure1.

Schematic presentation of the sub-region $19 q 13.3$ investigated in the current study.

Figure2.

Association of single polymorphisms with TTF (A) and OS (B) in multiple myeloma patients treated with high-dose treatment and stem cell support. The p value (logarithmic scale) for association of homozygous wild type carriers compared to all variant carriers of each marker with TTF and OS, are depicted against the position of the marker.

Figure 3.

Kaplan-Meier plots of TTF and OS. Combination analysis of CD3EAP G-21A or RAI-intron1-1 with NFKB1 -94ins/del. The numbers at risk at 24, 48, 72, 96 and 120 months are presented below the figure. Wild type carriers of either CD3EAP G-21A or RAI-intron1-1 in combination with wild type carriers of NFKB1 -94ins/del (solid blue line), variant type carriers of either CD3EAP G-21A or RAI-intron1-1 in combination with wild type carriers of NFKB1 -94ins/del (dashed blue line), wild type carriers of either CD3EAP G-21A or RAI-intron1-1 in combination with variant type carriers of NFKB1 -94ins/del (solid red line), variant type carriers of either CD3EAP G-21A or RAI-intron1-1 in combination with variant type carriers of $N F K B 1-94$ ins/del (dashed red line).

Figure 4.

Kaplan-Meier plots of A: TTF and B: OS. Patients treated with interferon- $\alpha$ in relation to genotypes of CD3EAP G$21 \mathrm{~A}$ or $R A I$-intron1-1 in combination with genotypes of $N F K B 1-94$ ins/del. The numbers of patients at risk at $0,24,48$, 72, 96 and 120 months are presented below the figure. Wild type carriers of either CD3EAP G-21A or RAI-intron1-1 in combination with wild type ins-allele carriers of NFKB1 -94ins/del (solid blue line), variant type carriers of either CD3EAP G-21A or RAI-intron1-1 in combination with wild type ins-allele carriers of NFKB1 -94ins/del (dashed blue line), wild type carriers of either CD3EAP G-21A or RAI-intron1-1 in combination with variant-type del-allele carriers 
of NFKB1 -94ins/del (solid red line), variant type carriers of either CD3EAP G-21A or RAI-intron1-1 in combination with variant type del-allele carriers NFKB1 -94ins/del (dashed red line).

\section{Acknowledgement:}

We thank Bettina Hansen and Lars Bentzen for expert technical assistance. Participants from the Nordic Myeloma Study Group (NMSG) are thanked. This work was supported by The Research Fund at Region Sjaelland. 


\section{Reference List}

1. Rockenbauer,E., Bendixen,M.H., Bukowy,Z., Yin,J., Jacobsen,N.R., Hedayati,M., Vogel,U., Grossman,L., Bolund,L., and Nexo,B.A. (2002) Association of chromosome 19q13.2-3 haplotypes with basal cell carcinoma: tentative delineation of an involved region using data for single nucleotide polymorphisms in two cohorts. Carcinogenesis, 23, 1149-1153.

2. Nexo,B.A., Vogel,U., Olsen,A., Ketelsen,T., Bukowy,Z., Thomsen,B.L., Wallin,H., Overvad,K., and Tjonneland,A. (2003) A specific haplotype of single nucleotide polymorphisms on chromosome 19q13.2-3 encompassing the gene RAI is indicative of postmenopausal breast cancer before age 55. Carcinogenesis, 24, 899-904.

3. Vogel,U., Laros,I., Jacobsen,N.R., Thomsen,B.L., Bak,H., Olsen,A., Bukowy,Z., Wallin,H., Overvad,K., Tjonneland,A., Nexo,B.A., and Raaschou-Nielsen,O. (2004) Two regions in chromosome 19q13.2-3 are associated with risk of lung cancer. Mutat.Res., 546, 65-74.

4. Vangsted,A., Gimsing,P., Klausen,T.W., Nexo,B.A., Wallin,H., Andersen,P., Hokland,P., Lillevang,S.T., and Vogel,U. (2007) Polymorphisms in the genes ERCC2, XRCC3 and CD3EAP influence treatment outcome in multiple myeloma patients undergoing autologous bone marrow transplantation. Int.J.Cancer, 120, 1036-1045.

5. de Boer,J. and Hoeijmakers,J.H. (2000) Nucleotide excision repair and human syndromes. Carcinogenesis, 21, 453-460.

6. Laska,M.J., Strandbygard,D., Kjeldgaard,A., Mains,M., Corydon,T.J., Memon,A.A., Sorensen,B.S., Vogel,U., Jensen,U.B., and Nexo,B.A. (2007) Expression of the RAI gene is conducive to apoptosis: studies of induction and interference. Exp.Cell Res., 313, 2611-2621.

7. Laska,M.J., Lowe,S.W., Zender,L., Hearn,S., Vogel,U., Jensen,U.B., Bric,A., and Nexo,B.A. (2009) Enforced expression of PPP1R13L increases tumorigenesis and invasion through p53dependent and p53-independent mechanisms. Mol.Carcinog., 48, 832-842.

8. Yang,J.P., Hori,M., Sanda,T., and Okamoto,T. (1999) Identification of a novel inhibitor of nuclear factor-kappaB, RelA-associated inhibitor. J.Biol.Chem., 274, 15662-15670.

9. Bergamaschi,D., Samuels,Y., O'Neil,N.J., Trigiante,G., Crook,T., Hsieh,J.K., O'Connor,D.J., Zhong,S., Campargue,I., Tomlinson,M.L., Kuwabara,P.E., and Lu,X. (2003) iASPP oncoprotein is a key inhibitor of p53 conserved from worm to human. Nat.Genet., 33, 162167.

10. Ochs,R.L., Stein,T.W., Jr., Chan,E.K., Ruutu,M., and Tan,E.M. (1996) cDNA cloning and characterization of a novel nucleolar protein. Mol.Biol.Cell, 7, 1015-1024.

11. Whitehead,C.M., Winkfein,R.J., Fritzler,M.J., and Rattner,J.B. (1997) ASE-1: a novel protein of the fibrillar centres of the nucleolus and nucleolus organizer region of mitotic chromosomes. Chromosoma, 106, 493-502. 
12. Yamazaki,T., Hamano,Y., Tashiro,H., Itoh,K., Nakano,H., Miyatake,S., and Saito,T. (1999) CAST, a novel CD3epsilon-binding protein transducing activation signal for interleukin-2 production in T cells. J.Biol.Chem., 274, 18173-18180.

13. Nissen,K.K., Vogel,U., and Nexo,B.A. (2009) Association of a single nucleotide polymorphic variation in the human chromosome 19q13.3 with drug responses in the NCI60 cell lines. Anticancer Drugs, 20, 174-178.

14. Vangsted,A.J., Klausen,T.W., Gimsing,P., Andersen,N.F., Abildgaard,N., Gregersen,H., and Vogel,U. (2009) A polymorphism in NFKB1 is associated with improved effect of interferon\{alpha\} maintenance treatment of patients with multiple myeloma after high-dose treatment with stem cell support. Haematologica, 94, 1274-1281.

15. Vangsted,A.J., Klausen,T.W., Andersen,N.F., Abildgaard,N., Gang,A.O., Gregersen,H., Vogel,U., and Gimsing,P. (2010) Improved survival of multiple myeloma patients with late relapse after high-dose treatment and stem cell support, a population-based study of 348 patients in Denmark in 1994-2004*. Eur.J.Haematol. .

16. Vangsted,A.J., Klausen,T.W., Andersen,N.F., Abildgaard,N., Gang,A.O., Gregersen,H., Vogel,U., and Gimsing,P. (2010) Improved survival of multiple myeloma patients with late relapse after high-dose treatment and stem cell support; A population-based study of 348 patients in Denmark in 1994-2004. Eur.J.Haematol..

17. Miller,S.A., Dykes,D.D., and Polesky,H.F. (1988) A simple salting out procedure for extracting DNA from human nucleated cells. Nucleic Acids Res., 16, 1215.

18. Saber,A.T., Nielsen,L.R., Dictor,M., Hagmar,L., Mikoczy,Z., and Wallin,H. (1998) K-ras mutations in sinonasal adenocarcinomas in patients occupationally exposed to wood or leather dust. Cancer Lett., 126, 59-65.

19. Vangsted,A.J., Klausen,T.W., Ruminski,W., Gimsing,P., Andersen,N.F., Gang,A.O., Abildgaard,N., Knudsen,L.M., Nielsen,J.L., Gregersen,H., and Vogel,U. (2009) The polymorphism IL-1beta T-31C is associated with a longer overall survival in patients with multiple myeloma undergoing auto-SCT. Bone Marrow Transplant., 43, 539-545.

20. Nexo,B.A., Vogel,U., Olsen,A., Nyegaard,M., Bukowy,Z., Rockenbauer,E., Zhang,X., Koca,C., Mains,M., Hansen,B., Hedemand,A., Kjeldgaard,A., Laska,M.J., RaaschouNielsen,O., Cold,S., Overvad,K., Tjonneland,A., Bolund,L., and Borglum,A.D. (2008) Linkage disequilibrium mapping of a breast cancer susceptibility locus near RAI/PPP1R13L/iASPP. BMC.Med.Genet., 9, 56.

21. Karban,A.S., Okazaki,T., Panhuysen,C.I., Gallegos,T., Potter,J.J., Bailey-Wilson,J.E., Silverberg,M.S., Duerr,R.H., Cho,J.H., Gregersen,P.K., Wu,Y., Achkar,J.P., Dassopoulos,T., Mezey,E., Bayless,T.M., Nouvet,F.J., and Brant,S.R. (2004) Functional annotation of a novel NFKB1 promoter polymorphism that increases risk for ulcerative colitis. Hum.Mol.Genet., 13, $35-45$.

22. Stark,G.R., Kerr,I.M., Williams,B.R., Silverman,R.H., and Schreiber,R.D. (1998) How cells respond to interferons. Annu.Rev.Biochem., 67, 227-264. 
23. Ghiringhelli,F., Apetoh,L., Tesniere,A., Aymeric,L., Ma,Y., Ortiz,C., Vermaelen,K., Panaretakis,T., Mignot,G., Ullrich,E., Perfettini,J.L., Schlemmer,F., Tasdemir,E., Uhl,M., Genin,P., Civas,A., Ryffel,B., Kanellopoulos,J., Tschopp,J., Andre,F., Lidereau,R., McLaughlin,N.M., Haynes,N.M., Smyth,M.J., Kroemer,G., and Zitvogel,L. (2009) Activation of the NLRP3 inflammasome in dendritic cells induces IL-1beta-dependent adaptive immunity against tumors. Nat.Med., 15, 1170-1178.

24. Hideshima,T., Ikeda,H., Chauhan,D., Okawa,Y., Raje,N., Podar,K., Mitsiades,C., Munshi,N.C., Richardson,P.G., Carrasco,R.D., and Anderson,K.C. (2009) Bortezomib induces canonical nuclear factor-kappaB activation in multiple myeloma cells. Blood, 114, 1046-1052. 
Figure 2.

A

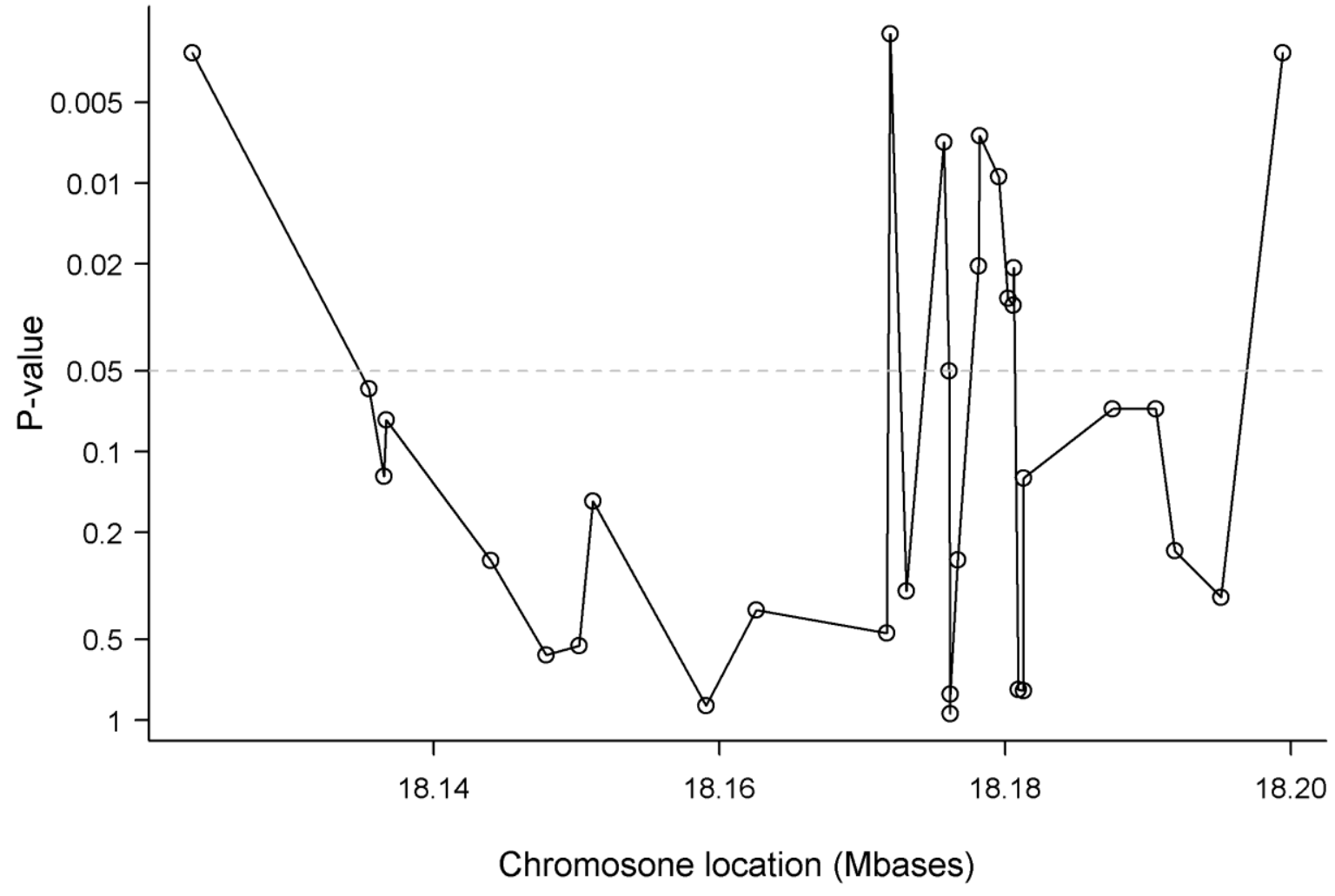

B

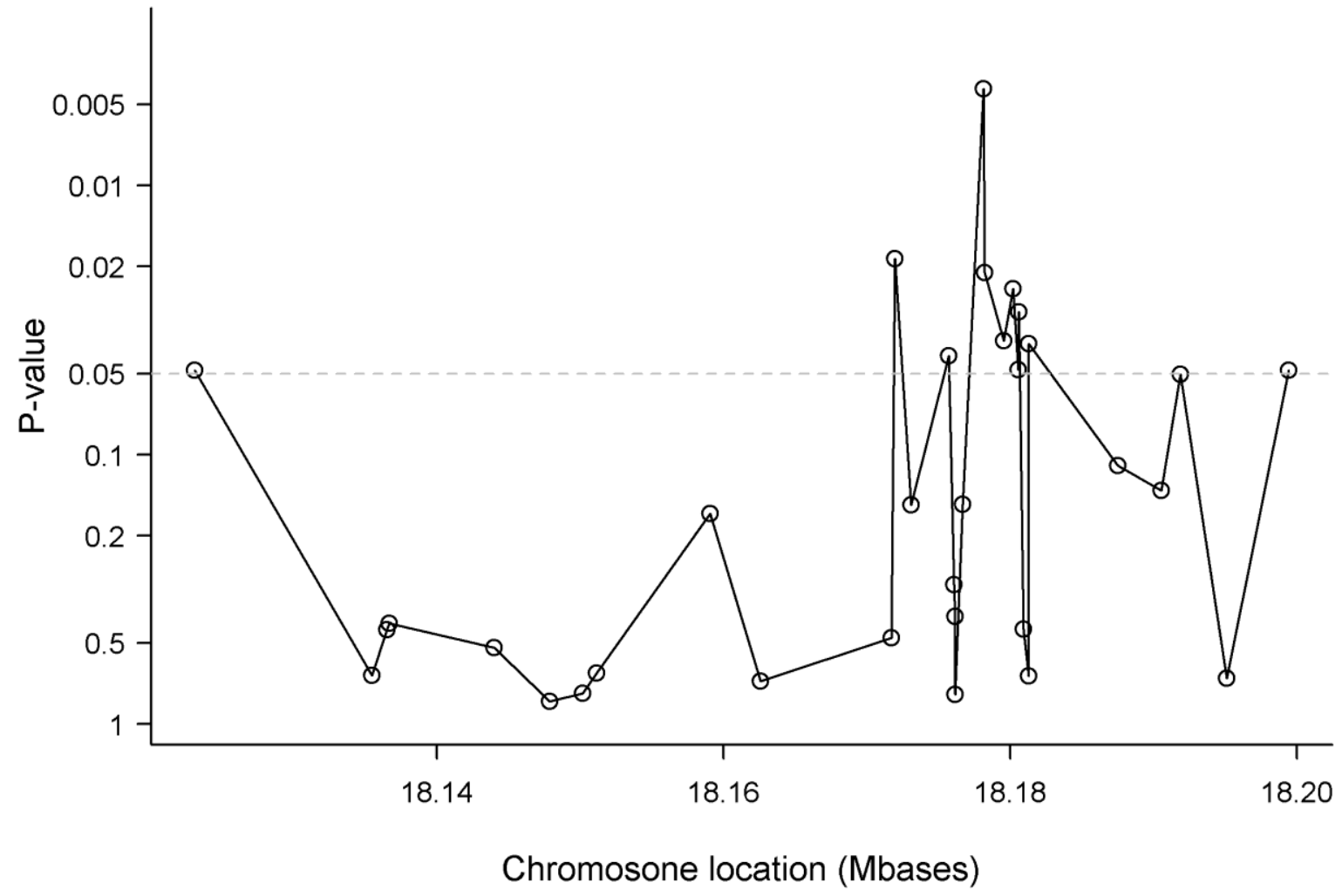


CD3EAP G-21A combined with NFKB1 -94 INS/DEL

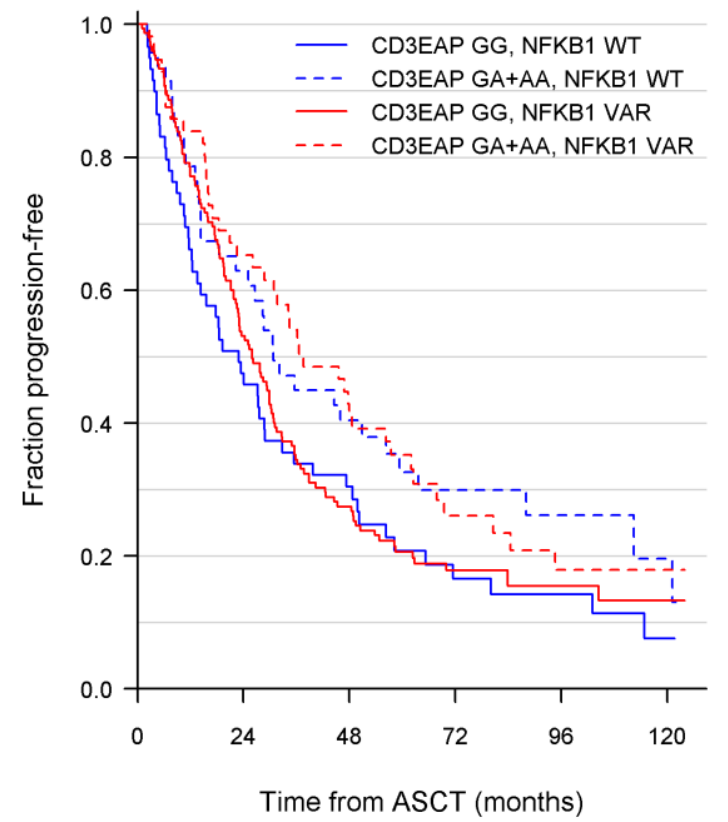

No. at risk

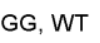

$G A+A A, W T$ GG, VAR

GA+AA, VAR

$\begin{array}{cccccc}60 & 28 & 16 & 7 & 5 & 1 \\ 47 & 28 & 18 & 10 & 6 & 3 \\ 155 & 77 & 38 & 17 & 9 & 4 \\ 58 & 35 & 23 & 11 & 6 & 4\end{array}$

RAl-intronl-I comb. with NFKB1 -94 INS/DEL

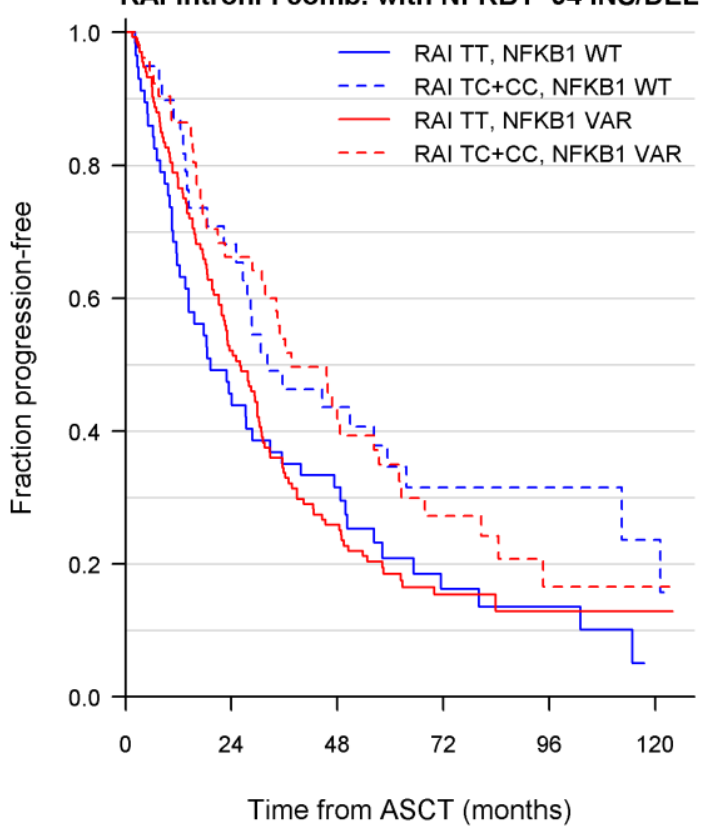

No. at risk

TT, WT

TC+CC, WT

TT, VAR

TC+CC, VAR

$\begin{array}{ccc}58 & 26 & 16 \\ 39 & 25 & 16 \\ 137 & 68 & 33 \\ 55 & 32 & 21\end{array}$

6
9
13
10

CD3EAP G-21A combined with NFKB1 -94 INS/DEL

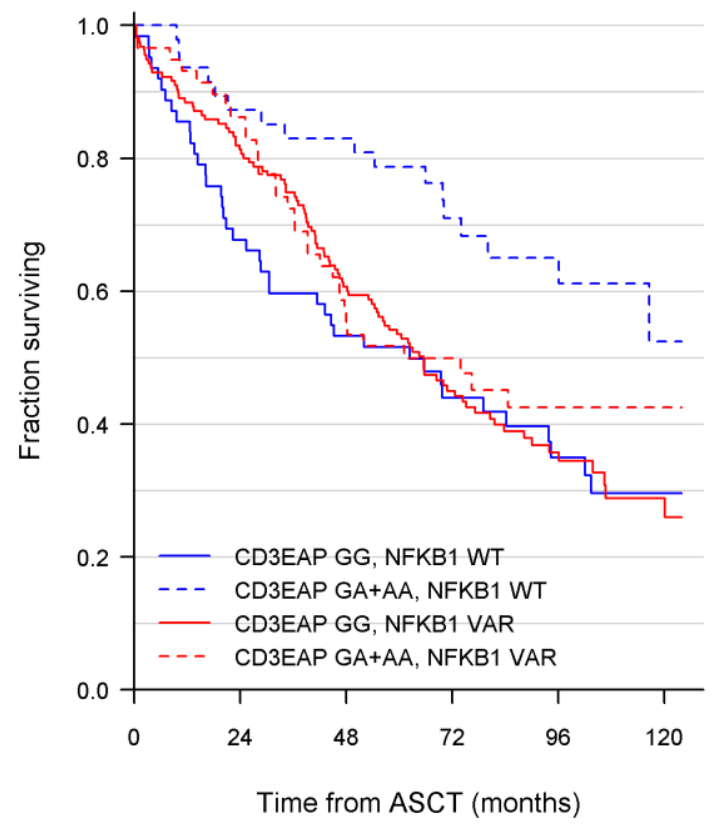

No. at risk

GG, WT GA+AA, WT $G G, V A R$ $G A+A A, V A R$

$\begin{array}{cccccc}62 & 42 & 33 & 22 & 15 & 6 \\ 47 & 41 & 39 & 26 & 17 & 6 \\ 155 & 126 & 94 & 55 & 30 & 10 \\ 58 & 50 & 33 & 24 & 12 & 9\end{array}$

RAl-intronl-I comb. with NFKB1 -94 INS/DEL

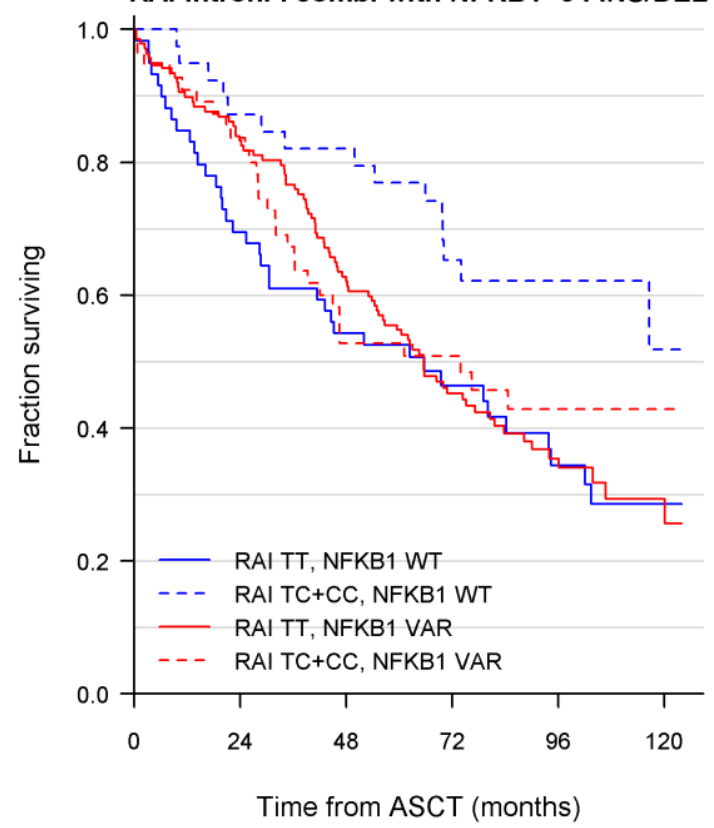

No. at risk

TT, WT TC+CC, WT TT, VAR $\mathrm{TC}+\mathrm{CC}, \mathrm{VAR}$

$\begin{array}{cccccc}59 & 41 & 32 & 21 & 14 & 5 \\ 39 & 34 & 32 & 21 & 14 & 5 \\ 137 & 114 & 86 & 49 & 26 & 8 \\ 55 & 46 & 29 & 23 & 10 & 7\end{array}$


CD3EAP G-21A combined with NFKB1 -94 INS/DEL

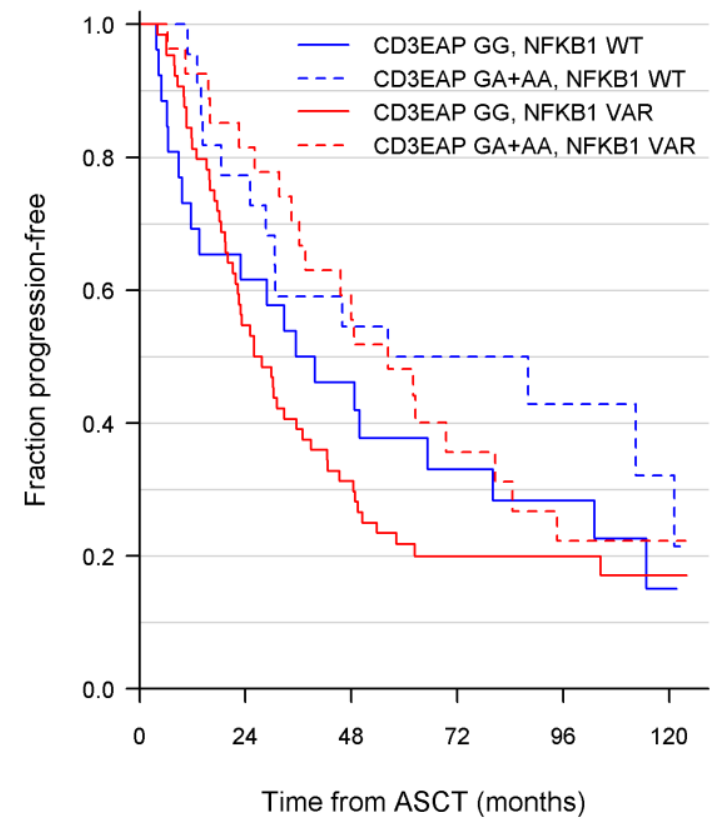

No. at risk

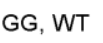

$G A+A A, W T$ GG, VAR

$G A+A A, V A R$

$\begin{array}{lllcll}26 & 16 & 11 & 7 & 5 & 1 \\ 22 & 17 & 12 & 9 & 5 & 3 \\ 64 & 35 & 20 & 11 & 8 & 4 \\ 27 & 22 & 16 & 8 & 5 & 3\end{array}$

RAI-intronl-I comb. with NFKB1 -94 INS/DEL

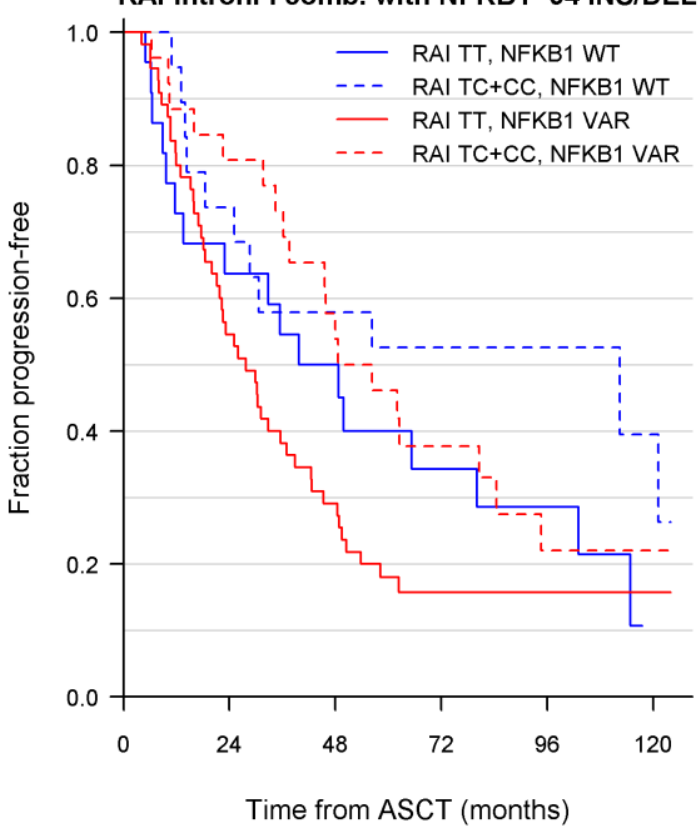

No. at risk

TT, WT

TC+CC, WT

TT, VAR

TC+CC, VAR

22
19
55
26

$\begin{array}{ll}14 & 10 \\ 14 & 11 \\ 30 & 16 \\ 21 & 15\end{array}$

$\begin{array}{ll}6 & 4 \\ 8 & 5 \\ 7 & 5 \\ 8 & 4\end{array}$

0
3
4
2

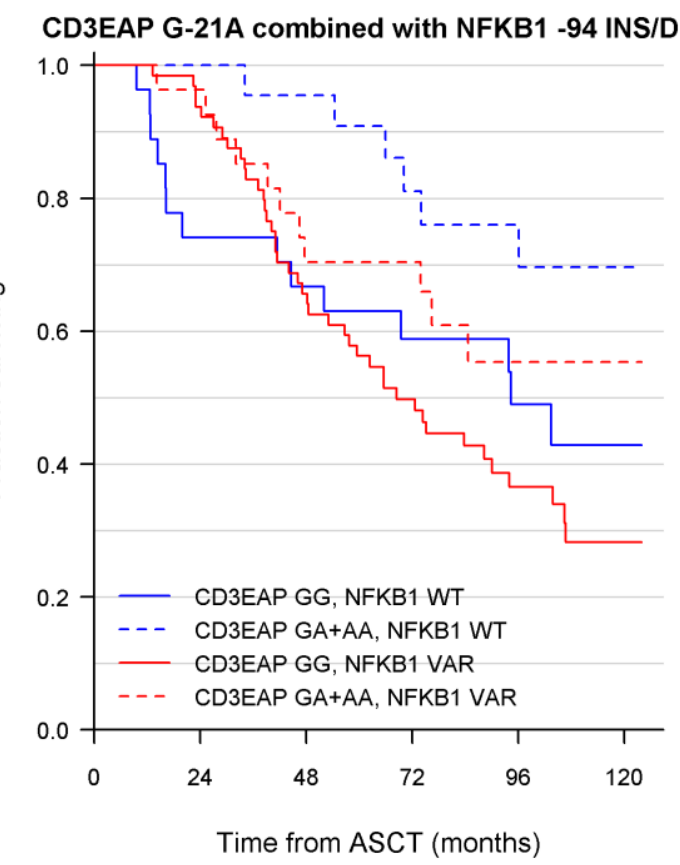

No. at risk

$\begin{array}{lllllll}\text { GG, WT } & 27 & 20 & 18 & 14 & 10 & 6 \\ \text { GA+AA, WT } & 22 & 22 & 21 & 16 & 12 & 6 \\ \text { GG, VAR } & 64 & 60 & 42 & 29 & 16 & 7 \\ \text { GA+AA, VAR } & 27 & 26 & 19 & 18 & 9 & 7\end{array}$

RAl-intronl-I comb. with NFKB1 -94 INS/DEL

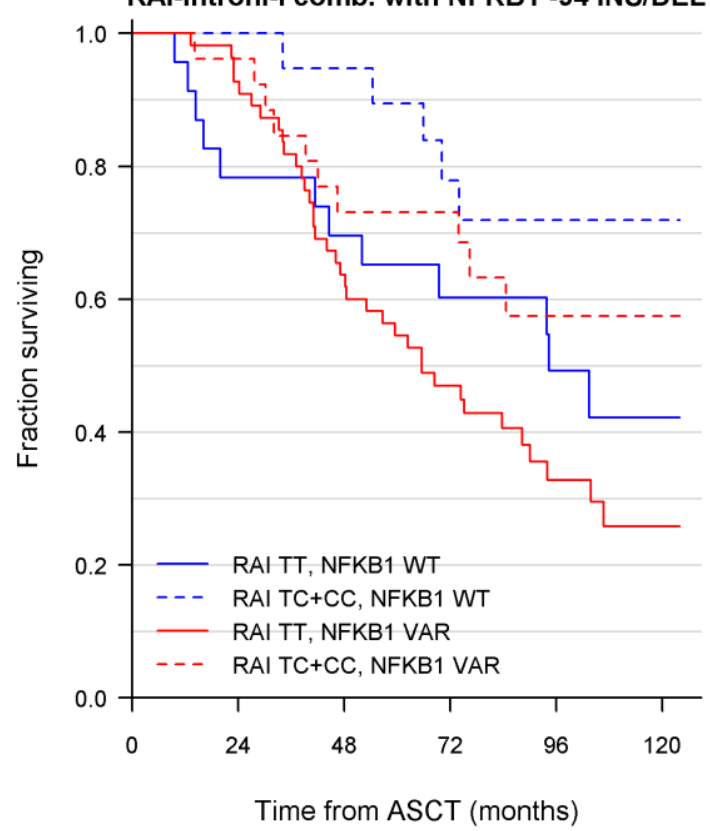

No. at risk

TT, WT

TC+CC, WT

TT, VAR

TC+CC, VAR

$\begin{array}{llllcl}23 & 18 & 16 & 12 & 9 & 5 \\ 19 & 19 & 18 & 13 & 9 & 5 \\ 55 & 51 & 35 & 23 & 12 & 5 \\ 26 & 25 & 19 & 18 & 8 & 6\end{array}$


Table 1. Patient characteristics at the time of diagnosis of 348 patients.

\begin{tabular}{|l|c|c|c|}
\hline & No of patients & Median & Range \\
\hline Sex & $204(59 \%)$ & & \\
Male & $144(41 \%)$ & & \\
Female & $246(71 \%)$ & 56 & $(28-69)$ \\
\hline Age & $101(29 \%)$ & & \\
$<60$ & 249 & 3.9 & $(1.2-57)$ \\
$>=60$ & 332 & 98 & $(47-833)$ \\
\hline$\beta 2-$-microglobulin $(\mathrm{mg} / \mathrm{dL})$ & 297 & 3.5 & $(0.25-5.3)$ \\
\hline Creatinine $(\mu \mathrm{mol} / \mathrm{L})$ & & & \\
\hline Albumin $(\mathrm{g} / \mathrm{dL})$ & $56(23 \%)$ & & \\
\hline ISS & $94(39 \%)$ & & \\
I & $89(37 \%)$ & & \\
II & $35(10 \%)$ & & \\
III & $77(23 \%)$ & & \\
\hline Durie-Salmon stage & $228(67 \%)$ & & \\
I & & 27.7 & $(23.4-30.8)$ \\
II & & 69.8 & $(60.5-81.6)$ \\
III & 177 & & \\
\hline TTF (months) & & & \\
\hline OS (months) & 74 & & \\
\hline Treated with thalidomide at & & & \\
relapse & & & \\
\hline Treatment with bortezomib at & & \\
relapse & & & \\
\hline
\end{tabular}




\begin{tabular}{|c|c|c|c|c|c|}
\hline Gene & Genotypes & $\mathbf{N}$ & $\begin{array}{l}\text { Median TTF } \\
\text { or TNT (mo) }\end{array}$ & HR $(95 \% C I)$ & p value \\
\hline \multicolumn{6}{|l|}{$R A I$-intron1-1 } \\
\hline+ INF- $\alpha$ & TT & 78 & 30.5 & 1 & \\
\hline \multirow[t]{3}{*}{+ INF- $\alpha$} & $\mathrm{TC}+\mathrm{CC}$ & 46 & 56.3 & $0.6(0.4-0.9)$ & 0.01 \\
\hline & TT & 116 & 21.7 & 1 & \\
\hline & $\mathrm{TC}+\mathrm{CC}$ & 42 & 28.7 & $0.8(0.5-1.2)$ & 0.23 \\
\hline \multicolumn{6}{|l|}{$R A I$-intron1-1 } \\
\hline + Thalidomide & TT & 113 & 10.7 & 1 & \\
\hline + Thalidomide & $\mathrm{TC}+\mathrm{CC}$ & 41 & 7.2 & $1.0(0.6-1.4)$ & 0.87 \\
\hline \multicolumn{6}{|l|}{$R A I$-intron1-1 } \\
\hline+ Bortezomib & TT & 43 & 8.9 & 1 & \\
\hline + Bortezomib & $\mathrm{TC}+\mathrm{CC}$ & 16 & 13.2 & $0.6(0.3-1.3)$ & 0.22 \\
\hline \multicolumn{6}{|l|}{ CE3EAP G-21A } \\
\hline + Thalidomide & GG & 121 & 10.2 & 1 & \\
\hline + Thalidomide & $\mathrm{AG}+\mathrm{AA}$ & 51 & 9.1 & $0.9(0.6-1.2)$ & 0.39 \\
\hline \multicolumn{6}{|c|}{ CE3EAP G-21A } \\
\hline+ Bortezomib & GG & 49 & 8.6 & 1 & \\
\hline
\end{tabular}




\begin{tabular}{|c|c|c|c|c|c|c|}
\hline+ Bortezomib & & $\mathrm{AG}+\mathrm{AA}$ & 22 & 13.3 & $0.6(0.3-1.1)$ & 0.06 \\
\hline \multicolumn{7}{|c|}{ NFKB 1-94 INS/DEL combined with $C D 3 E A P$ G-21A } \\
\hline$+\mathrm{IFN}-\alpha$ & ins & GG & 27 & 37.6 & 1 & \\
\hline$+\mathrm{IFN}-\alpha$ & ins & $\mathrm{AG}+\mathrm{AA}$ & 22 & 56.4 & $0.6(0.3-1.3)$ & \\
\hline$+\mathrm{IFN}-\alpha$ & Ins/del + del & GG & 64 & 26.0 & $1.2(0.7-2.0)$ & \\
\hline$+\mathrm{IFN}-\alpha$ & Ins/del + del & $\mathrm{AG}+\mathrm{AA}$ & 27 & 56.3 & $0.7(0.4-1.4)$ & 0.1 \\
\hline \multicolumn{7}{|c|}{ NFKB 1-94 INS/DEL combined with $C E 3 E A P$ G-21A } \\
\hline & ins & GG & 33 & 17.7 & 1 & \\
\hline & ins & $\mathrm{AG}+\mathrm{AA}$ & 23 & 22.3 & $0.7(0.4-1.2)$ & \\
\hline & Ins/del + del & GG & 86 & 26.2 & $0.6(0.4-0.9)$ & \\
\hline & Ins/del + del & $\mathrm{AG}+\mathrm{AA}$ & 27 & 28.7 & $0.6(0.3-1.0)$ & 0.1 \\
\hline \multicolumn{7}{|c|}{ NFKB1-94 INS/DEL combined with $R A I$-intron1-1 } \\
\hline$+\mathrm{IFN}-\alpha$ & ins & TT & 23 & 39.8 & 1 & \\
\hline$+\mathrm{IFN}-\alpha$ & ins & $\mathrm{TC}+\mathrm{CC}$ & 19 & 112.4 & $0.6(0.3-1.3)$ & \\
\hline$+\mathrm{IFN}-\alpha$ & Ins/del + del & TT & 56 & 27.8 & $1.4(0.8-2.4)$ & \\
\hline$+\mathrm{IFN}-\alpha$ & Ins/del + del & $\mathrm{TC}+\mathrm{CC}$ & 26 & 52.5 & $0.8(0.4-1.5)$ & 0.04 \\
\hline \multicolumn{7}{|c|}{ NFKB1-94 INS/DEL combined with $R A I$-intron1-1 } \\
\hline & ins & TT & 34 & 15.6 & 1 & \\
\hline & ins & $\mathrm{TC}+\mathrm{CC}$ & 18 & 32.2 & $0.6(0.3-1.1)$ & \\
\hline & Ins/del + del & TT & 79 & 24.3 & $0.6(0.4-1.0)$ & \\
\hline & Ins/del + del & $\mathrm{TC}+\mathrm{CC}$ & 24 & 28.7 & $0.6(0.3-1.0)$ & 0.12 \\
\hline
\end{tabular}

Table 2 Univariate analysis of the effect of genotypes on treatment outcome of INF- $\alpha$, thalidomide and bortezomib.

Abbreviations: $\mathrm{CI}=$ confidence interval; $\mathrm{HR}=$ hazard ratio; $\mathrm{TTF}=$ time-to-treatment failure; $\mathrm{TNT}$ : time-to-next treatment; OS= overall survival; mo = months; $\infty$ : indicates that median survival was not reached 